\title{
Correction to: Wave Polarization Analyzed by Singular Value Decomposition of the Spectral Matrix in the Presence of Noise
}

\author{
Ulrich Taubenschuss $^{1}$ (D) . Ondřej Santolík ${ }^{1,2}$ (D)
}

Published online: 14 November 2018

(C) The Author(s) 2018

\section{Correction to: Surveys in Geophysics https://doi.org/10.1007/s10712-018-9496-9}

The article Wave Polarization Analyzed by Singular Value Decomposition of the Spectral Matrix in the Presence of Noise, written by Ulrich Taubenschuss and Ondřej Santolík, was originally published electronically on the publisher's internet portal (currently SpringerLink) on 19 August 2018 without open access.

With the authors' decision to opt for Open Choice the copyright of the article changed on 13 November 2018 to () The Author(s) 2018 and the article is forthwith distributed under the terms of the Creative Commons Attribution 4.0 International License (http:// creativecommons.org/licenses/by/4.0/), which permits use, duplication, adaptation, distribution and reproduction in any medium or format, as long as you give appropriate credit to the original authors and the source, provide a link to the Creative Commons license and indicate if changes were made.

The original article has been corrected.

The original article can be found online at https://doi.org/10.1007/s10712-018-9496-9.

Ulrich Taubenschuss

ut@ufa.cas.cz

1 Institute of Atmospheric Physics, Czech Academy of Sciences, Bočni II/1401, 14131 Prague, Czech Republic

2 Faculty of Mathematics and Physics, Charles University, V Holešovičkách 2, 18000 Prague, Czech Republic 